\title{
Papillary Thyroid Cancer Association with the Use of Infertility Drugs Case Report and Literature Review
}

\author{
Sanna Salam¹, Nusha Fareen ${ }^{2}$, Stuart Morduchowitz ${ }^{3}$, Issac Sachmechi ${ }^{4}$ \\ ${ }^{1}$ Internal Medicine Department, Icahn School of Medicine of Mount Sinai Queens Hospital Centre, New York, NY, USA \\ ${ }^{2}$ Hackensack Meridian, Internal Medicine Department, Jersey Shore University Medical Center, Neptune City, NY, USA \\ ${ }^{3}$ Endocrinology Department, Northwell Hospital, New Hyde Park, NY, USA \\ ${ }^{4}$ Endocrinology Department, Icahn School of Medicine of Mount Sinai Queens Hospital Centre, New York, NY, USA \\ Email: drsanama_leo@yahoo.com
}

How to cite this paper: Salam, S., Fareen, N., Morduchowitz, S. and Sachmechi, I. (2021) Papillary Thyroid Cancer Association with the Use of Infertility Drugs Case Report and Literature Review. Open Journal of Endocrine and Metabolic Diseases, 11, 155-159.

https://doi.org/10.4236/ojemd.2021.118013

Received: June 25, 2021

Accepted: August 28, 2021

Published: August 31, 2021

Copyright $\odot 2021$ by author(s) and Scientific Research Publishing Inc. This work is licensed under the Creative Commons Attribution International License (CC BY 4.0).

http://creativecommons.org/licenses/by/4.0/

\begin{abstract}
Recently, the incidence of papillary thyroid cancer increases rapidly than any other type of cancer worldwide, without the age and gender discrimination. Environmental or therapeutic exposure of radiation is main culprit of papillary thyroid cancer, but there is limited research available to support that to the usage of infertility drug associated with papillary thyroid cancer. We presented the rare and interesting case of papillary thyroid cancer while patient was on clomiphene citrate for the management of infertility. We found few studies which showed pathophysiology connection between in CC and papillary cell carcinoma.
\end{abstract}

\section{Keywords}

Endocrinology, Thyroid Infertility

\section{Introduction}

The thyroid gland is one of the essential endocrine glands in the human body located in front of the neck. It uses iodine to produce hormone which regulates body temperature, heart rate, blood pressure and metabolic rate [1]. Thyroid cancer is most rapidly increasing cancer in men and women since 1975. The incidence of thyroid cancer has increased nearly three times, mostly the increase in papillary thyroid cancer (PTC). Risk factor for thyroid cancer can be hereditary, familial or environmental like exposure to the radiation, low iodine diet. We publish an article about the high association between use of artificial sweetener 
and well differentiated thyroid cancer (WDTC). There is minimal data suggesting correlation between use of hormonal therapy and papillary thyroid cancer. According to the American cancer society, the estimated numbers of new cases thyroid cancer in 2020 will be 52,890 , out of which 40,170 thyroid cancer will be in females [2]. Papillary thyroid cancer has higher incidence but with better prognosis [3].

\section{Case Report}

Prior ethical consent was taken for the case. A 44-year-old female with history of infertility, microprolactinemia, hyperthyroidism presented with right supraclavicular mass. Patient was on regular endocrine follow up for last 2 years, taking propylthiouracil and cabergoline and her hyperthyroidism was well controlled. For last one year patient started infertility treatment with clomiphene and then switched to gonadotropin therapy. Patient noticed two small area of swelling in right side of the neck which rapidly increased in size and presented to us after 9 months.

There was no clear symptom of hypothyroidism or hyperthyroidism. No complain of shortness of breath, neck pain, dysphasia, palpitation, dizziness, headache, visual problem or weight loss. No sign of Cushing syndrome, acromegaly or galactorrhea. No family history of thyroid disease or any cancer. No history or smoking or alcohol. Menstruation was regular since she started her infertility treatment one year back.

On examination thyroid was enlarged and nodular but no clear nodule was found (Figure 1). CBC, electrolyte and thyroid function tests were normal. Ultrasound of the neck revealed a multi nodular goiter with $2.3 \mathrm{~cm}$ calcified nodule with two complex cysts $(4.4 \times 3.4 \mathrm{~cm}$ and $4.1 \times 3.6)$ on the right side of the neck. Subsequent CT scan showed multi nodular goiter with multiple node involvement with tracheal deviation to right (Figure 2). FNA of thyroid nodule showed atypia of undetermined significance (AUS) and neck node showed metastatic

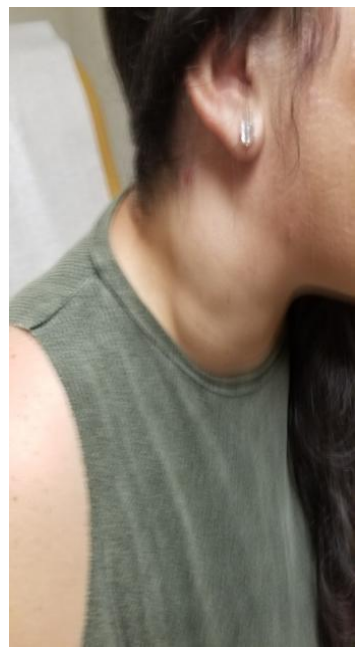

Figure 1. Enlarged thyroid with multiple cervical lymphaden Fopathy. 


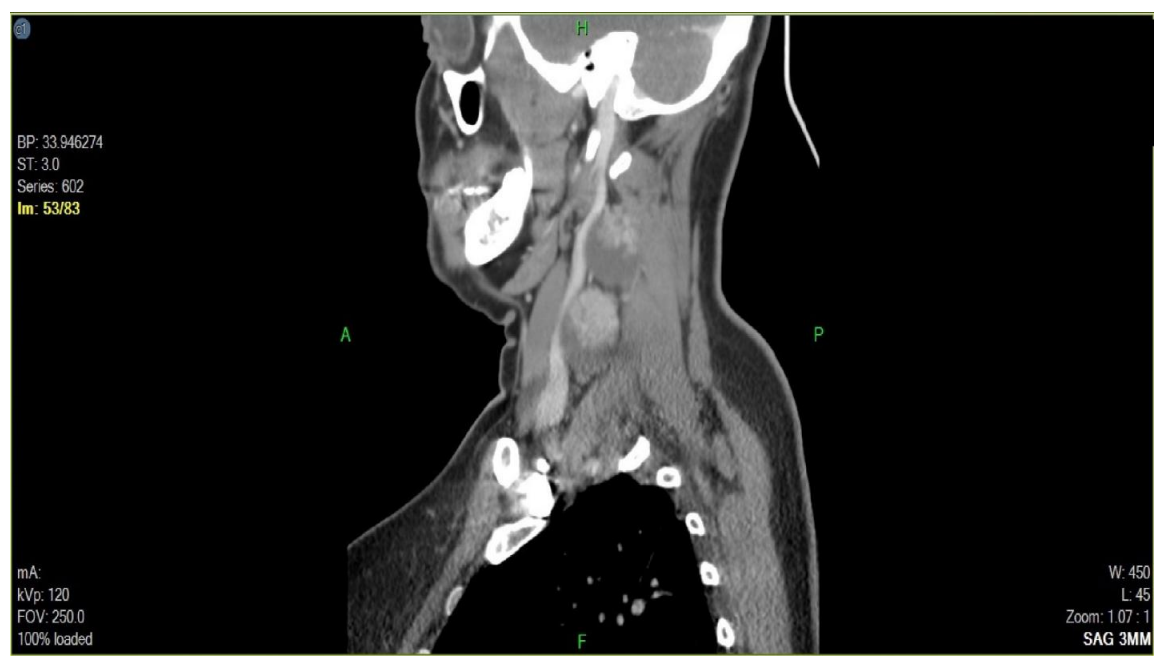

Figure 2. Enlarged, pathologic, cystic lymph nodes. Possibly from Thyroid. Asymmetrically mildly enlarged right thyroid lobe.

papillary thyroid carcinoma. Patient went for total thyroidectomy and right modified neck dissection followed by I-131 therapy. It was T2N1bM0 stage I, TG 59 , TG Ab $<20$. Histology showed papillary cancer with tall cell variant, without perineural invasion and margin involvement. Multiple cervical lymph nodes were positive, largest measuring $4.5 \mathrm{~cm}$. Molecular studies were negative. The patient had uneventful postoperative recovery. Patient was on frequent follow up with endocrinologist and no post-operative complication noticed after 2 years of surgery.

\section{Discussion}

Most of the hormone-sensitive cancers, like ovarian, breast, endometrial, cervical, and less common colorectal, melanoma, and thyroid cancer trigger in the female reproductive age [4] [5].

Exogenous intake of hormone-like contraceptive pills and pregnancies are one of the culprits. The female infertility ratio increases $1537.35 / 10,000$ according to 2017 updates and 48.5 million couples suffer from infertility issues. As infertility rises, more patients undergoing infertility treatment [6] [7] and fertility drugs cause the release of endogenous hormones and induction of ovulation. Thyroid carcinoma is also showed a strong correlation in patients who taking clomiphene citrate (CC) estrogen, progesterone for infertility with high Relative risk but less significantly raised of cancer with the use of GnRH, hCG, or gonadotropins [1] [8].

Patients were assisted reproductive treatment showed aggressive papillary carcinoma after a few years of treatment [9] CC have apoptotic, cytotoxic, and antioxidative potential in nature [10].

During Gestation, TSH secretion increases, Fertility drugs cause ovarian sensitization directly or indirectly beside increased release of TSH, and thyroid tissue exhibit estrogen receptors cause proliferation of glands. The Alpha receptor 
expression of the thyroid gland have similar in male and female however beta-receptor revealed substantial expression after the stimulation of 17beta-estradiol level in female, instigates of thyroid cell and manifestation on cyclin D1, Aprotein, responsible for vigorous cell cycle, this process is slow after the exposure of 17-beta estradiol along with its influence on mitogen-activated protein (MAP) kinase [5] [10]. CC has been in practice for decades since 1967 and its trigger indirectly ovarian induction. The use of cc has multiple reasons as the low-cost, non-significant risk of ovarian hyperstimulation and oral intake [10]. AST (assisted reproductive technique) causes the highest chance to develop thyroid cancer in nulliparous women with CC (clomiphene citrate) and it's also proved that higher dose of CC related to a higher chance to thyroid cancer [2].

\section{Conclusion}

This case report with extensive literature review and studies has proven that fertility drugs particularly CC have robust association to cultivate papillary thyroid tumor, and continuous monitoring is required in patients during and after exposure of these fertility medications.

\section{Conflicts of Interest}

The authors declare no conflicts of interest regarding the publication of this paper.

\section{References}

[1] Nguyen, Q.T., Lee, E.J., Huang, M.G., Park, Y.I., Khullar, A. and Plodkowski, R.A. (2015) Diagnosis and Treatment of Patients with Thyroid Cancer. American Health \& Drug Benefits, 8, 30-40.

[2] http://www.cancer.org/cancer/acs-medical-content-and-news-staff.html

[3] Okani, C.O., Otene, B., Nyaga, T., et al. (2015) Report of a Case of Papillary Thyroid Carcinoma in Association with Hashimoto's Thyroiditis. Nigerian Medical Journal, 56, 433-435. https://doi.org/10.4103/0300-1652.171612

[4] Hannibal, C.G., Jensen, A., Sharif, H. and Kjaer, S.K. (2008) Risk of Thyroid Cancer after Exposure to Fertility Drugs: Results from a Large Danish Cohort Study. $\mathrm{Hu}$ man Reproduction, 23, 451-456.

[5] Brinton, L.A., Moghissi, K.S., Scoccia, B., et al. (2015) Effects of Fertility Drugs on Cancers Other Than Breast and Gynecologic Malignancies. Fertility and Sterility, 104, 980-988. https://doi.org/10.1016/j.fertnstert.2015.06.045

[6] Sun, H., Gong, T.T., Jiang, Y.T., Zhang, S., Zhao, Y.H. and Wu, Q.J. (2019) Global, Regional, and National Prevalence and Disability-Adjusted Life-Years for Infertility in 195 Countries and Territories, 1990-2017: Results from a Global Burden of Disease Study, 2017. Aging (Albany NY), 11, 10952-10991. https://doi.org/10.18632/aging.102497

[7] Mascarenhas, M.N., Flaxman, S.R., Boerma, T., Vanderpoel, S. and Stevens, G.A. (2012) National, Regional, and Global Trends in Infertility Prevalence since 1990: A Systematic Analysis of 277 Health Surveys. PLoS Medicine, 9, e1001356.

[8] Yu, Q., Lv, X., Liu, K., et al. (2018) Fertility Drugs Associated with Thyroid Cancer 
Risk: A Systematic Review and Meta-Analysis. BioMed Research International, 2018, Article ID: 7191704. https://doi.org/10.1155/2018/7191704

[9] Momenimovahed, Z., Taheri, S., Tiznobaik, A. and Salehiniya, H. (2019) Do the Fertility Drugs Increase the Risk of Cancer? A Review Study. Frontiers in Endocrinology (Lausanne), 10, 313.

[10] Yilmaz, S., Yilmaz Sezer, N., Gönenç, I.M., Ilhan, S.E. and Yilmaz, E. (2018) Safety of Clomiphene Citrate: A Literature Review. Cytotechnology, 70, 489-495. https://doi.org/10.1007/s10616-017-0169-1 